\title{
Dime qué armas y te diré qué eres. Construcción de coaliciones en Argentina, 1995-2015*
}

Tell me what you assemble and I will tell you what you are. Electoral coalition building in Argentina, 1995-2015

\section{FACUNDO CRUZ}

Universidad Argentina de la Empresa, Argentina.

Universidad de Buenos Aires, Argentina.

cruzfacu@gmail.com

La dinámica competitiva argentina ha adquirido un componente coalicional en las últimas dos décadas. Con posterioridad a la reforma constitucional de 1994, cada vez más partidos políticos privilegian la formación de acuerdos conjuntos con distintos socios para competir por cargos públicos en juego. El presente trabajo tiene por objeto plantear que la construcción de coaliciones electorales es una decisión estratégica de las elites partidarias. Pueden privilegiar dos modelos distintos de construcción: hacerlo por penetración territorial o por difusión territorial. El modelo privilegiado guarda relación con el grado de acuerdo electoral que alcanzan las elites partidarias. Aplico este análisis a las coaliciones presidenciales y de diputados nacionales que compitieron en el país entre 1995 y 2015.

\section{Introducción}

La formación de coaliciones electorales se ha convertido en una estrategia predominante en los sistemas políticos latinoamericanos (Clerici et. al., 2016, Machado, 2017). El aumento de la fragmentación de los sistemas partidarios, en paralelo a regímenes jurídicos que suelen facilitar e incentivar estos acuerdos (Clerici y Scherlis, 2014), han contribuido a que la disputa política esté dominada por acuerdos entre múltiples partidos políticos que se fijan objetivos comunes y ponen a disposición sus propios recursos para conseguirlos (Chasquetti, 2008).

* El autor agradece los aportes de dos evaluadores anónimos de Revista SAAP a una versión previa de este artículo. También a los comentaristas, expositores, organizadores y asistentes de dos paneles celebrados en el XIII Congreso Nacional y VI Internacional sobre Democracia (Rosario, septiembre de 2018) y en el $14^{\circ}$ Congreso Nacional de Ciencia Política (San Martín, Provincia de Buenos Aires, julio de 2019). Por último, a Lara Goyburu y Paula Clerici, quienes hicieron valiosos aportes a versiones originales de este trabajo. 
El caso argentino no escapa a esa tendencia (Escolar, 2014; Clerici, 2015 y 2018; Mauro, 2018; Cruz, 2018 y 2019b). Este fenómeno se ha acrecentado como una respuesta estratégica al proceso de «territorialización» partidaria que ha caracterizado al país en las últimas dos décadas (Calvo y Escolar, 2005; Leiras, 2007 y 2010; Clerici, 2014; Varetto 2017; Cruz, 2019a y 2019b). Un sistema partidario desnacionalizado aumenta los incentivos para que se formen coaliciones electorales. Las elites partidarias toman determinadas decisiones para lograr sus propios objetivos colectivos e individuales, buscando que las organizaciones partidarias de las que forman parte sobrevivan (Panebianco, 1990; Mair y Katz, 1995). En escenarios de fragmentación regional desequilibrada (Navarro y Varetto, 2014) los dirigentes partidarios tienen un menú de opciones para elegir a sus socios: realizan un diagnóstico y fijan un curso de acción. Este proceso, sigue las metas definidas por ellos mismos para alcanzar los logros partidarios que consideren pertinentes.

En virtud de ello, las coaliciones que deciden formar tienen diferencias entre sí: hay distintos modelos de construcción. Estos modelos, por su parte, generan un problema de coordinación electoral que impacta en el grado de acuerdo que logran en los distritos. De modo que, cen qué medida el modelo de construcción coalicional está asociado a grados variables de acuerdo multinivel? Este trabajo busca aportar elementos teóricos y empíricos para responder a este interrogante, sin ánimos de encontrar una relación causal pero sí cierto grado de correlación entre las variables. Planteo que las coaliciones electorales en sistemas presidenciales ${ }^{1}$ deben ser estudiadas desde una perspectiva multinivel y pueden seguir dos caminos posibles: se conforman por difusión territorial o por penetración territorial. Mientras que las primeras están asociadas a mayores grados de acuerdo entre los partidos que las integran, las segundas lo están a menores. Planteo testear esta relación en la Argentina entre los años 1995 y 2015, tomando 25 casos de coaliciones electorales multinivel que compitieron por el cargo de presidente y de diputados nacionales.

El artículo se organiza de esta manera. En primer lugar, desarrollo algunos supuestos teóricos. En segundo lugar, preciso detalles sobre el marco legal argentino para encarar este estudio y, posteriormente, sobre la metodología de investigación. Luego de ello, describo el universo de análisis, clasifico los casos según ambos modelos y explico la correlación entre las variables. Finalmente, sintetizo con conclusiones.

No niego que en sistemas parlamentarios las coaliciones electorales adquieran la misma condición de multinivel. Sin embargo, el análisis acá expuesto se centra en sistemas presidenciales y en las coaliciones que se forman para alcanzar el máximo cargo en disputa. 


\section{Un marco teórico para estudiar las coaliciones electorales multinivel ${ }^{2}$}

Las coaliciones electorales multinivel son 1) acuerdos que están integrados por varios partidos que 2) disponen de recursos electorales propios para 3) acceder a cargos ejecutivos nacionales y subnacionales en 4) un sistema de partidos multinivel ${ }^{3}$. Se entienden como un mecanismo de «coordinación política»: son «procesos mediante los cuales [...] los políticos coordinan sus acciones electorales con el fin de ganar más escaños legislativos o carteras ejecutivas» (Cox, 2000, p. 49) .

Los sistemas políticos son multinivel en tanto 1) los partidos políticos compiten en distintos niveles y distritos en el territorio, 2) los electores cuentan con varios votos con el fin de 3) elegir entre distintos contendientes para 4) distintos cargos públicos y 5) mediados por diferentes tipos de reglas electorales (Došek y Freidenberg, 2013). Lo que caracteriza a estos sistemas políticos es la existencia de tantos niveles de competencia como niveles de autoridades electas existan. Me centraré principalmente en dos niveles de competencia electoral: el nacional y el provincial.

Podemos esperar que si los partidos políticos deciden competir por la mayor cantidad de cargos en juego (nacionales y provinciales), deban recurrir a las coaliciones como una estrategia para aumentar su caudal electoral para cumplir distintos objetivos políticos: obtener una mayor cantidad de cargos públicos (legislativos y ejecutivos), superar el mínimo de votos exigido por ley para ingresar en el reparto de esos cargos, adquirir más financiamiento público, mantener su personería jurídica, etc.

Estos procesos pueden seguir dos modelos posibles, los cuales delinean las principales estrategias de construcción coalicional que definen las elites partidarias a la hora de competir en sistemas presidenciales (Cruz, 2019a). El primero se denomina penetración territorial. En estos casos, la construcción de la coalición se realiza desde un centro político que controla, estimula y desarrolla su crecimiento y extensión hacia la periferia. Ese «centro político» está asociado geográficamente a un determinado distrito desde el cual se busca dar el «salto» de la coalición hacia otras provincias o regiones, para aumentar el caudal electoral y posicionar a los candidatos, el programa de

2 Para una discusión más amplia sobre este apartado, recomiendo un artículo ya publicado al respecto (Cruz 2019a).

3 Esta definición está formulada en base a la propuesta por Chasquetti (2008), quien la toma de Strom (1990) y la adapta a los sistemas presidenciales.

4 Cox (2000) entiende que la coordinación electoral se produce tanto entre dirigentes políticos como entre los electores. En esta investigación nos concentramos únicamente en la primera dimensión. 
gobierno, el logo, etc. Está representado en una mesa directiva de dirigentes que define los plazos, las etapas y los tiempos en los cuales se procede para extenderla al resto de los distritos. Adicionalmente, este crecimiento territorial se realiza sobre una estructura política que no siempre está presente en la mayor parte de los distritos.

En este proceso de construcción la relación entre el «centro político»y los dirigentes de otros distritos es asimétrica: es el primero el que tiene capacidad y autonomía decisora para definir candidaturas, (la mayoría de) los miembros de la coalición y el programa de gobierno, por ejemplo. A medida que la coalición se va extendiendo hacia otros distritos, quienes son los responsables provinciales de conformarla siguen los lineamientos generales establecidos en el centro. Esto no implica que los acuerdos partidarios que se conformen en otras provincias tengan nula capacidad decisora, sino que las cuestiones más relevantes que definen los plazos, las pautas y las reglas de construcción de la coalición multinivel son fijadas mayormente por el «centro político».

Un modelo alternativo de construcción de la coalición es el de difusión territorial. A diferencia del anterior, en estos casos la conformación del acuerdo se da por «generación espontánea» (Panebianco, 1990, p. 110) entre los distintos partidos políticos que lo conforman. El modelo de construcción se lleva a cabo sobre una estructura política que ya se encuentra extendida en el territorio nacional. Las elites nacionales y provinciales acuerdan un nombre y un logo para la coalición, definen las candidaturas a distintos cargos en juego, establecen las reglas de convivencia, etc. Este proceso se lleva a cabo en una gran cantidad de distritos posibles de manera simultánea. Estas elites con asiento en las provincias deciden darle forma al acuerdo nacional, el cual se integra con acuerdos locales.

En este tipo de construcciones también hay un fuerte componente territorial, pero, a diferencia del anterior, en el modelo de difusión no hay un alto grado de control de parte de un «centro». Los partidos que conforman la coalición en cada distrito tienen un mayor grado de autonomía y capacidad decisora para definir cuestiones relevantes, como pueden ser las candidaturas en el distrito, la adaptación de la plataforma de gobierno al distrito específico, etc. Existen ciertos lineamientos generales establecidos que deben ser respetados por todos los distritos, pero se deja un mayor margen de acción a cada uno. El «bastión electoral» no es uno solo, sino que son varios los distritos desde los cuales se construye la coalición electoral multinivel. De esta forma, la relación entre las elites partidarias que integran la coalición es más simétrica: hay balance y equilibrio entre todos los distritos en los cuales se conforma el acuerdo. 


\section{El contexto legal de la competencia electoral en Argentina}

El proceso de construcción de las coaliciones electorales multinivel se da en un marco legal determinado, el cual fija ciertas reglas que los partidos deben seguir. Este marco estructura un conjunto de incentivos que facilitan o perjudican la conformación de esos acuerdos, promoviendo ciertas prácticas y desalentando otras. Los dirigentes partidarios nacionales y provinciales, toman decisiones estratégicas determinadas dentro de un marco de reglas que establece limitaciones a la hora de construir coaliciones electorales multinivel. Esto impacta directamente en la construcción de acuerdos. Argentina, en comparación con otros países latinoamericanos, deja un amplio margen de acción para que las coaliciones electorales multinivel sean más territorializadas que nacionalizadas (Clerici y Scherlis, 2014). Por esa razón creo conveniente destinar unas breves líneas resaltando los elementos más relevantes para el análisis posterior.

La Argentina está constituida por 23 provincias y la Ciudad Autónoma de Buenos Aires. Se caracteriza por un sistema federal con un régimen electoral interconectado de actores, reglas y normas (Calvo y Escolar, 2005; Escolar, 2014): hay uno por cada provincia, uno por la Ciudad Autónoma de Buenos Aires y uno nacional. La legislación nacional establece las reglas para la elección del presidente y vicepresidente de la Nación, los diputados nacionales y los senadores nacionales.

Según la Ley Orgánica de Partidos Políticos (N. ${ }^{\circ}$ 23.298) y las distintas leyes provinciales existen cuatro tipos de partidos políticos. Me concentraré en tres de ellos ${ }^{5}$. Los provinciales son aquellos que pueden presentar candidatos solo para gobernador y legisladores en una provincia. Los partidos de distrito, en cambio, tienen las mismas características jurídicas que los provinciales, salvo que pueden presentarse con candidatos a cargos legislativos nacionales (diputados y senadores) en la provincia donde tienen reconocimiento jurídico. Los partidos nacionales, por último, son aquellos partidos de distrito que reciben reconocimiento en cinco provincias o más. Pueden postularse con candidatos para competir por la Presidencia y Vicepresidencia de la Nación.

¿Dentro de qué marco legal se conforman las alianzas electorales? La legislación reconoce que son los partidos nacionales y de distrito los que pueden establecer acuerdos electorales para competir por los cargos en juego, los cuales 1) tienen carácter transitorio (sólo se constituye para una elección específica) y 2) no subrogan los derechos partidarios al acuerdo electo-

El cuarto tipo de partido político son los vecinales. Son aquellos facultados para competir únicamente por la Intendencia, los cargos del Concejo Deliberante y los Consejos Escolares. Reciben reconocimiento de la justicia provincial. 
ral. Pero no todos los partidos pueden participar de todas las coaliciones. La legislación nacional expresamente reconoce que los partidos nacionales son los únicos que pueden formar coaliciones electorales para la competencia presidencial. Los partidos de distrito pueden integrar estos acuerdos, pero siempre que no formen parte de un partido nacional. También pueden formar alianzas de distrito, las cuales 1) están habilitadas para competir por las bancas de diputados y senadores nacionales, 2) independientemente de los acuerdos que se construyan para competir por el cargo presidencial, pero 3) pueden presentarse solamente en la provincia donde tengan reconocimiento de la justicia federal.

De esta forma, la legislación nacional les otorga a los partidos de distrito un alto margen de autonomía para conformar coaliciones independientemente de cómo se estructuren los demás acuerdos nacionales y provinciales. Se abre la puerta así para que los acuerdos que buscan construirse en el nivel nacional y en cada uno de los distritos no siempre sean los mismos, o bien no estén integrados por todos los socios. De esta manera, el modelo de construcción privilegiado por las elites partidarias guarda una relación con el grado de acuerdo multinivel que alcanzan al competir por distintos cargos en juego, como pueden ser las bancas legislativas.

\section{Metodología de investigación}

Este trabajo se inscribe en una línea de investigación que destaca la importancia de estudiar fenómenos políticos complejos con $N$ chico (George y Bennet, 2005; Goertz y Mahoney, 2012). Esto adquiere relevancia al estudiar política subnacional (Suárez-Cao, Batlle y Wills-Otero, 2017) o multinivel: se pueden obtener inferencias causales válidas con un alto conocimiento de los casos estudiados. A partir del marco teórico desarrollado, planteo indagar en las 25 coaliciones electorales presidenciales para hacer foco en la correlación entre el modelo de construcción coalicional y el grado de acuerdo multinivel alcanzado. Estos casos 1) compitieron entre 1995 y 2015 por los cargos de presidente y vicepresidente, y de diputados nacionales, que 2) obtuvieron más del $1,5 \%$ de los votos válidos emitidos ${ }^{6}$. Los mismos pueden

Por dos razones. Primero, la Reforma Constitucional de 1994 modificó las reglas de elección presidencial, pasando del Colegio Electoral al sistema de mayoría absoluta atenuada con ballotage (Nohlen, 1994). Este cambio impactó en la dinámica de la competencia electoral y alteró radicalmente las reglas que gobiernan el sistema partidario nacional. De esta manera, descarto las nuevas reglas institucionales como un factor importante que inciden en el fenómeno estudiado. Segundo, la reforma política impulsada por el Gobierno Nacional en el año 2009 y aprobada en el año 2010 incluyó la celebración de un sistema de Primarias Abiertas, Simultáneas y 
ser entendidos como coaliciones electorales multinivel dado que, aunque el cargo legislativo es nacional, la definición de la candidatura (De Luca, Jones y Tula, 2002 y 2008) y la presentación de la lista se hace a nivel distrital (provincial). Existe así una relación entre dos niveles de competencia que puede ser estudiada empíricamente y problematizada teóricamente.

A continuación, desarrollo las dos variables propuestas: grado de acuerdo multinivel y modelo de construcción coalicional.

\section{a.Grado de acuerdo multinivel}

Esta variable busca capturar el resultado de la estrategia electoral privilegiada por las elites partidarias. La construyo a partir de observar cada uno de los 25 casos de estudio en las 24 provincias del país para la competencia por el cargo de diputados nacionales entre 1995 y 2015 (total de 600 observaciones). Comparo integrantes de la coalición electoral presidencial versus integrantes de la coalición electoral legislativa: las unidades de observación son los partidos integrantes de los acuerdos que se presentan como tales ante la justicia electoral argentina y reconocidos por la legislación.

El grado de acuerdo multinivel de las coaliciones discute con la literatura especializada que toma en cuenta como principal variable dependiente de los modelos estadísticos a la congruencia (Downs, 1998; Stefuriuc, 2013; Clerici, 2014; Cruz 2014). Esta medida comúnmente utilizada evalúa si los integrantes de las alianzas que compiten en un nivel (por ejemplo, el nacional) son los mismos o distintos en otro nivel (por ejemplo, el provincial o local). En aquellos casos en los cuales, en niveles inferiores participen del acuerdo partidos provinciales o simplemente aquellos que no integran el acuerdo a nivel nacional, entonces las coaliciones tienden a ser más incongruentes. $\mathrm{Si}$, en cambio, fueran siempre los mismos, entonces aumentan los niveles de congruencia.

Este consenso generalizado, sin embargo, no toma en cuenta dos elementos que son comunes en la política partidaria multinivel. En primer lugar, en algunos casos latinoamericanos son los líderes en el nivel subnacional los que toman las decisiones referidas a la estrategia electoral (Devoto y Olmeda, 2017). Esto es una característica propia de la dinámica competitiva argentina (De Luca, Jones y Tula, 2002 y 2008; Calvo y Escolar, 2005; Leiras, 2007; Gervasoni, 2012; Lodola, 2012; Escolar, 2014). De modo que en los

Obligatorias (PASO) para los cargos nacionales. Adicionalmente, estableció que aquellas coaliciones electorales que no superaran el 1,5\% de los votos válidos quedaran fuera de competencia. Dado que las PASO solo se utilizaron en dos elecciones dentro de la base de datos construida (2011 y 2015) apliqué este criterio establecido para seleccionar los casos durante todo el período estudiado. 
niveles inferiores pueden estar presentes actores que son relevantes en el territorio, están concentrados en un determinado distrito y no tienen una extensión mayor hacia otras unidades subnacionales. Estos apoyos locales pueden aportar y reforzar los recursos políticos con los que cuentan las coaliciones electorales multinivel que compiten por los distintos cargos en juego. Esto puede llevar, tal como mencioné anteriormente, a que los actores subnacionales decidan ampliar los miembros de la coalición en ese nivel (Méndez de Hoyos, 2012; Miño, 2014).

De esta manera, si utilizara un concepto y una medida comúnmente aceptada como es la de congruencia estaría dando una relevancia destacada al hecho de que existen actores importantes en algunas regiones del país que se integran al acuerdo. Y, como consecuencia de ello, estaría caracterizando a una coalición como incongruente cuando, en realidad, fue parte de un proceso de construcción deliberadamente planeado por las elites partidarias para potenciar las chances de alcanzar los objetivos propuestos por quienes construyen el acuerdo. La clasificación de las coaliciones electorales según una determinada tipología resulta relevante en tanto las características que adquiere son consecuencia de quienes motorizan esos acuerdos.

En segundo lugar, del trabajo de campo realizado en un trabajo de investigación más amplio (Cruz 2018 y 2019b), se desprende que quienes son los encargados de impulsar los acuerdos electorales, no toman como un factor distorsivo que a nivel provincial o local se sumen actores políticos que no integran las coaliciones en el nivel nacional. Para mencionar un ejemplo, un dirigente nacional y diputado provincial de la Coalición Cívica-ARI señaló que: «Una vez tomada la decisión, fijamos la estrategia nacional y luego la derramamos hacia los distritos. Respetando sus realidades locales. Pero siguiendo la estrategia nacional $»^{7}$.

La regla de «lo que abunda no daña» pareciera ser una máxima de la política partidaria y electoral argentina. En cierta medida, la principal preocupación de los dirigentes partidarios consiste en que aquellos partidos que forman las coaliciones nacionales tienen que integrar también las coaliciones provinciales o de distrito. En aquellos casos donde no ocurre es donde existen tensiones internas en partidos políticos y coaliciones electorales multinivel: son los dirigentes en las provincias, los que tienen que balancear sus campañas electorales para evitar que la competencia en el distrito no afecte el desempeño de los candidatos presidenciales en la competencia nacional. Esto, en algunos casos específicos, suele impactar en las reglas internas de los acuerdos y genera rispideces que pueden impactar en los objetivos comunes propuestos.

Entrevista realizada a un dirigente nacional y diputado provincial de la Coalición Cívica-ARI, en el marco del trabajo de campo desarrollado para la tesis doctoral de la cual se desprende este trabajo. 
Por los argumentos expuestos, no considero que resulte un aspecto fundamental tomar en cuenta a todos los miembros de una coalición para evaluar cuándo son los mismos o si son distintos. Propongo una medida alternativa denominada grado de acuerdo multinivel: tomo en cuenta de manera agregada si en el nivel de distrito (provincial) los integrantes de las coaliciones electorales presidenciales forman también una coalición electoral legislativa para diputados nacionales. En este sentido, observo y evalúo el nivel subnacional respecto del nivel nacional de competencia.

Tal como indiqué en el apartado anterior, la normativa electoral argentina ofrece a las elites partidarias un menú de opciones bastante amplio para definir las estrategias electorales de acuerdo con cada escenario. Identifico cada una de ellas como una estrategia de competencia específica y le asigno una categoría concreta. El resultado final arroja cuatro opciones que tienen las elites partidarias para definir el grado de acuerdo multinivel alcanzado.

Denomino a la primera de ellas como «juntos»: refiere a aquellos casos en donde todos los miembros de la coalición electoral presidencial que tienen reconocimiento distrital, compiten conjuntamente en la misma coalición electoral legislativa para diputados nacionales. Esto se considera como el máximo grado de acuerdo posible alcanzado dado que, si bien no siempre todos los partidos tienen presencia en todo el territorio, todos aquellos que sí lo logran definen un mismo nombre, un logo conjunto, una plataforma electoral común y la distribución de candidaturas entre todos los socios. Son coaliciones articuladas. La segunda categoría, en cambio, es una variante alternativa que es común en la dinámica competitiva argentina pero no así en América Latina (Clerici y Scherlis, 2014). Es la categoría "colectora» y refiere a todos aquellos casos en donde se alcanzó un grado de acuerdo entre los partidos políticos, pero presentan listas legislativas distintas adheridas a la candidatura presidencial. Entiendo que hay cierto consenso entre los partidos integrantes, pero no es tan alto como en la categoría anterior dado que los logos, los nombres de las coaliciones y las candidaturas son distintas coaliciones electorales legislativas. La candidatura presidencial, en cambio, es la misma, para la cual buscan «arrastrar» votos con sus respectivas listas de diputados nacionales y, generalmente, coinciden en la plataforma de campaña. Son coaliciones acopladas.

La tercera categoría es «separados»: concentra aquellos casos en donde al menos uno de los miembros de la coalición electoral presidencial, compite sin aliarse en la coalición electoral legislativa en una provincia determinada porque se presenta con su propia lista (sin candidatura presidencial) o en otra coalición electoral legislativa. En estas situaciones el grado de acuerdo multinivel, es aún menor dado que se presenta la posibilidad de construir un consenso en torno a los candidatos en un distrito, pero no se concreta. Son coaliciones descoordinadas. 
Denomino a la última categoría como «solos/sin lista». Aquí se presentan aquellos casos en donde en una provincia para diputados nacionales se presenta solo uno de los partidos que integra la coalición electoral presidencial, ya sea porque es el único que tiene reconocimiento jurídico provincial o porque los demás socios deciden no presentarse. También contempla escenarios en donde ninguno de los partidos que integran la coalición electoral presidencial se presenta con una lista. Ambas situaciones, por otro lado, son unificadas dentro de la misma categoría. Esto se debe a que los partidos que deciden construir una coalición electoral en el nivel nacional no integran partidos que tengan reconocimiento en la mayoría o la totalidad de los distritos del país, ni tampoco logran acuerdos con partidos de distrito que no forman parte de otras coaliciones electorales presidenciales. Ya sea por estrategia electoral, definición de candidaturas, o por falta de coincidencias ideológicas o programáticas, estos partidos que acuerdan en el nivel nacional no encuentran correlato en la construcción en las provincias. Estas decisiones en el nivel nacional impactan en cada distrito. De esta forma, denomino estos casos como coaliciones desconectadas dado que ambos niveles de competencia aparecen disociados: hay un acuerdo para la candidatura presidencial (nacional) pero no se conforman acuerdos para diputados nacionales (distrital).

Una vez que defino las cuatro categorías que conforman las estrategias de competencia que tienen disponible los partidos políticos en el menú de opciones disponibles, determino cuál de ellas se lleva a cabo en cada una de las provincias del país. Una vez culminada esa tarea, obtengo la proporción de provincias que se enmarca en cada uno de ellos. Esto me permite conocer, para cada coalición electoral presidencial, cuál es la distribución estratégica privilegiada en la competencia por cargos legislativos. Pero, ¿̇cómo definir una de las cuatro opciones estratégicas por sobre las demás? Para hacerlo sigo estos pasos:

1. Agrupo las estrategias de competencia en dos macro categorías: grado alto-medio de acuerdo multinivel para «juntos» $\mathrm{y}$ «colectora» por un lado, y grado medio-bajo de acuerdo multinivel para «separados» $\mathrm{y}$ «solos/sin lista» por el otro.

2. Sumo la proporción correspondiente a cada una de ellas y observo dónde se ubica más del $50 \%$ de las provincias.

3. Una vez elegida una de las dos macro categorías, observo cuál de las dos subcategorías («juntos» / «colectora» o «separados» / «solos/sin lista») concentra la mayor cantidad de distritos.

4. Asigno a cada caso el grado de acuerdo alcanzado y clasifico el caso.

A continuación, sintetizo lo desarrollado en los párrafos anterior para esquematizar de manera más clara lo expuesto. 


\section{Facundo Cruz}

\section{TABLA 1}

Estrategia electoral, criterios de clasificación y grado de acuerdo de las coaliciones

\begin{tabular}{|c|c|c|c|}
\hline $\begin{array}{c}\text { Estrategia } \\
\text { electoral }\end{array}$ & Criterios & $\begin{array}{c}\text { Grado de } \\
\text { acuerdo } \\
\text { multinivel }\end{array}$ & $\begin{array}{c}\text { Clasificación del } \\
\text { caso }\end{array}$ \\
\hline Juntos & $\begin{array}{c}\text { Todos los integrantes de la coalición electoral } \\
\text { nacional presentes en el distrito compiten } \\
\text { conjuntamente para diputados nacionales }\end{array}$ & Grado alto & $\begin{array}{c}\text { Coalición } \\
\text { articulada }\end{array}$ \\
\hline Colectora & $\begin{array}{c}\text { Hay al menos dos listas de diputados nacionales que } \\
\text { adhieren a una misma candidatura presidencial }\end{array}$ & Grado medio-alto & Coalición acoplada \\
\hline Separados & $\begin{array}{c}\text { Al menos uno de los partidos políticos que integran } \\
\text { la coalición electoral nacional decide 1) competir por } \\
\text { fuera del acuerdo electoral legislativo o 2) forma } \\
\text { parte de otra coalición electoral en el distrito. }\end{array}$ & Grado medio-bajo & $\begin{array}{c}\text { Coalición } \\
\text { descoordinada }\end{array}$ \\
\hline Solos/sin lista & $\begin{array}{c}\text { 1) Solo uno de los partidos políticos decide competir } \\
\text { o tiene reconocimiento jurídico en el distrito; 2) No } \\
\text { integran otros partidos políticos en un acuerdo de } \\
\text { distrito; 3) ninguno compite en las elecciones } \\
\text { legislativas y la coalición electoral presidencial solo } \\
\text { presenta la fórmula ejecutiva nacional. }\end{array}$ & Grado bajo & $\begin{array}{c}\text { Coalición } \\
\text { desconectada }\end{array}$ \\
\hline
\end{tabular}

Fuente: Elaboración propia.

\section{GRÁFICO 1}

\section{Criterios de clasificación para los casos}

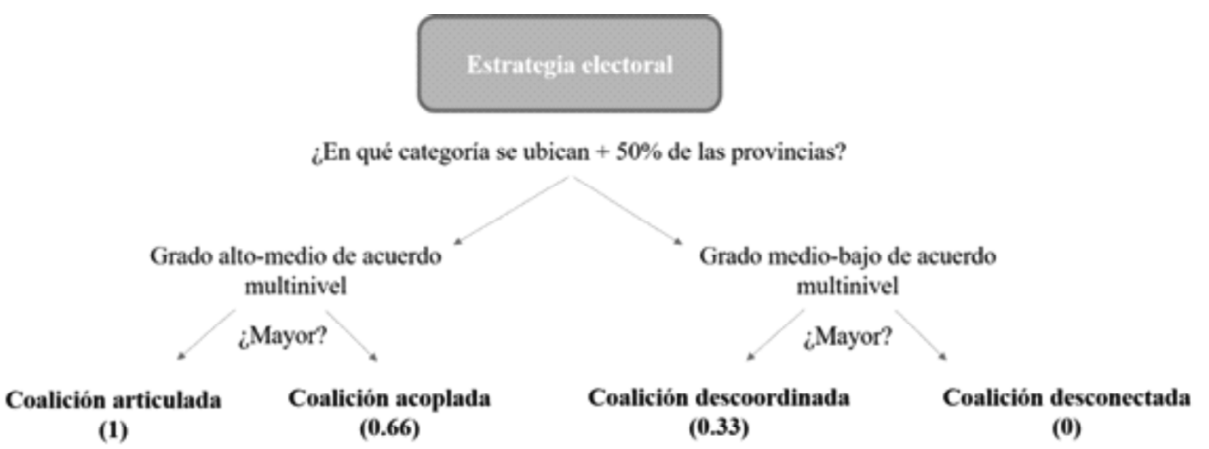

Fuente: Elaboración propia.

\section{a.Modelo de construcción coalicional}

El modelo de construcción coalicional tiene relación con el grado de acuerdo alcanzado por las elites partidarias. Para determinar cuándo las coaliciones se forman por difusión territorial o por penetración territorial tomo en cuenta dos dimensiones. 
En primer lugar, la mesa directiva de una coalición electoral multinivel. Sigo una línea de investigación que considera que las elites partidarias tienen una impronta importante a la hora de definir la estrategia de competencia. A diferencia de otros trabajos que toman en cuenta las señales que emite el sistema partidario (Clerici, 2014), creo que los actores toman decisiones, las cuales impactan en la dinámica de competencia partidaria y generan determinados efectos (Reynoso, 2011). Esas decisiones y esos efectos pueden ser medidos, evaluados y analizados empíricamente.

Una de las principales condiciones que está asociada al grado de acuerdo multinivel definido por los partidos políticos es el conjunto de dirigentes que adoptan las decisiones estratégicas de la coalición. Estos actores definen la estrategia electoral, el nombre del acuerdo, las reglas de convivencia entre los socios, el reparto de los cargos, los distritos donde se compiten, los aliados que (no) forman parte, etc. Son los puntos de acuerdo que tienen que alcanzar los partidos (Zelaznik, 2001; Carroll, 2007) y los recursos que comparten entre sí (Chasquetti, 2008). Esta mesa está constituida por aquellos responsables políticos que controlan las áreas de incertidumbre (Panebianco, 1990) de la coalición. Ésta puede estar concentrada en un grupo reducido de bastiones electorales o puede distribuirse entre varios: mientras la mesa directiva concentre mayor cantidad de dirigentes de una provincia específica, más desequilibrada estará y será más desbalanceada; mientras que, si está más distribuida entre varios distritos, entonces será más balanceada. Un mayor balance contribuye a que el grado de acuerdo multinivel alcanzado por los actores sea mayor, mientras que el desbalance lo reduce.

Para operacionalizarla tomo en cuenta la procedencia geográfica de aquellos que fueron reconocidos como los responsables ${ }^{8}$ de construir la coalición electoral presidencial a partir de entrevistas semi-estructuradas (Cruz, 2018). Identifico la provincia del país donde cada uno tuvo una trayectoria política reconocida y utilizo el indicador de fragmentación de Rae (1967) para evaluar el grado de concentración (desbalance) o dispersión geográfica (balance) de la mesa directiva. Está basada en el índice de HirschmannHenfindalh $(\mathrm{HH})$, cuya fórmula es

$$
\mathrm{HH}=\sum_{j}^{J}=1 P_{j}^{e}
$$

De esta manera, mientras el indicador se acerque más a 1 el modelo de construcción coalicional se caracteriza por una mesa directiva balanceada. En cambio, mientras más se acerca a 0 , el modelo será diagramado por una

Tomo en cuenta candidatos presidenciales, responsables de definir listas de diputados nacionales, apoderados y jefes de campaña. 
mesa directiva desbalanceada. Por último, defino la siguiente escala para ordenar los casos:

- 1: aquellos casos en los cuales el Índice de Rae se ubica entre 1 y 0,7 .

- 0.66: aquellos casos en los cuales el Índice de Rae se ubica entre 0,50 y 0,69 .

- 0.33: aquellos casos en los cuales el Índice de Rae se ubica entre 0,30 y 0,49 .

- 0: aquellos casos en los cuales el Índice de Rae se ubica entre 0 y 0,29 .

La segunda dimensión del modelo de construcción coalicional es la estructura política con la que cuentan los socios. Todo acuerdo entre partidos políticos que buscan competir por determinados cargos públicos en juego, necesita de organizaciones partidarias que estén localizadas en el territorio para presentar candidatos, movilizar el electorado, distribuir recursos, etc. Las elites partidarias que toman las decisiones estratégicas sobre la coalición electoral multinivel necesitan de una estructura partidaria para poder competir.

Para operacionalizarla considero el tipo de partido político con los cuales los dirigentes de la mesa directiva deciden construir el acuerdo electoral. Diferencio y calculo la proporción de partidos que forman parte de la coalición a partir del reconocimiento jurídico que adquiere cada uno por la legislación argentina. En América Latina, la normativa electoral establece qué partidos políticos pueden integrar coaliciones electorales según el nivel del sistema político donde se conformen (Clerici y Scherlis, 2014). Como indiqué anteriormente, en Argentina las coaliciones electorales presidenciales pueden estar formadas por partidos nacionales y por partidos de distrito: los primeros son aquellos que tienen una amplia extensión en el territorio nacional, mientras que los segundos están más concentrados en una determinada provincia.

Dado que el universo de análisis es complejo y variado (Mahoney, 2001; Falleti y Lynch, 2009) tengo que seguir reglas claras para determinar si la estructura política está extendida o concentrada en el país. Primero, calculo la proporción de provincias en las cuales los partidos políticos nacionales tenían reconocimiento jurídico de distrito al momento de conformarse la coalición electoral presidencial. Los partidos de distrito, por definición, tienen reconocimiento solamente en una provincia del país. Una vez realizado este cálculo, evalúo solamente la extensión que tuvieron todos los partidos políticos nacionales que conformaron todas las coaliciones analizadas du- 
rante el período 1995-2015. En términos absolutos, los partidos políticos nacionales que forman parte de la base de datos tuvieron reconocimiento jurídico en casi 11 provincias (10,37 de media y 6,7 de desvío estándar). Esto también se puede calcular en proporciones: el resultado arroja que el total de partidos políticos nacionales de la base tuvo reconocimiento jurídico en $43 \%$ de las provincias (28\% de desvío estándar). De esta manera, establezco como criterio de corte en 12 provincias (50\% del territorio), como el requisito necesario para considerar cuando los actores que formaron las coaliciones tuvieron una estructura política que abarca la mayor parte del territorio y, en consecuencia, se acercaron más al modelo de difusión territorial. Los casos que se alejan, son modelos de construcción por penetración territorial.

Por lo tanto, los valores asignados siguen este criterio:

- 1: si al menos 2 partidos políticos nacionales tuvieron presencia en 12 distritos o más.

- 0.66: si 1 partido tuvo presencia en 12 distritos o más y otros partidos nacionales sumaron 12 distritos o más, o partidos de distrito sumaron 12 distritos o más.

- 0.33: si 1 partido nacional tuvo 12 distritos o más y junto a otro nacional superaron los 12 (pero este segundo no tiene más de 12 distritos), o si ningún partido nacional tuvo 12 distritos por sí solo, pero 2 partidos nacionales sumaron 12 distritos o los partidos de distrito sumaron 12 distritos.

- 0: si ningún partido nacional llegó a 12 distritos, ni los partidos nacionales sumados llegaron a 12 distritos, ni los partidos de distritos sumaron 12 distritos.

De la combinación de ambas dimensiones surge este esquema para ordenar los casos según el modelo de construcción coalicional. 


\section{GRÁFICO 2}

Combinación de dimensiones mesa directiva y estructura política

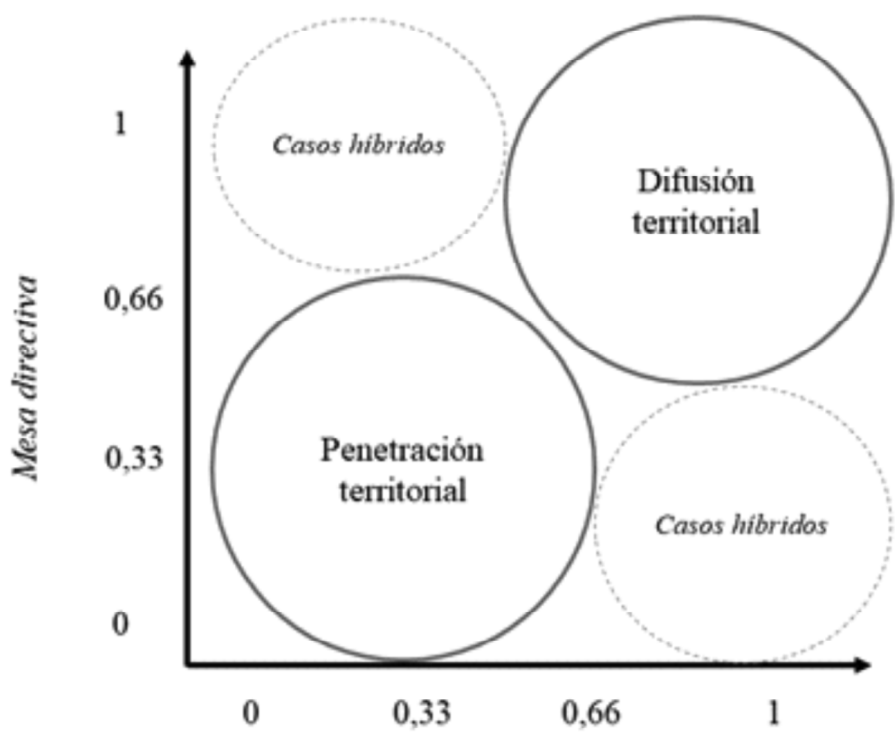

Estructurapolitica

Fuente: elaboración propia.

En términos teóricos, se pueden dar tres situaciones: 1) casos de coaliciones electorales multinivel que tengan su estructura política concentrada/ extendida y su mesa directiva (des)balanceada, según corresponda para cada modelo de construcción; 2) otras donde una de ellas puede tener una estructura política bien extendida en el territorio, pero un conjunto de dirigentes que tomen las decisiones que estén concentrados en una región del país; o bien 3) una mesa directiva balanceada entre distintos distritos y una estructura política poco extendida. Dado que ambas dimensiones tienen la misma escala ordinal se pueden clasificar los casos en base a ciertos criterios. De modo que, al asignar un valor a cada caso para cada dimensión, puede haber igualdad (por ejemplo, 0,66 en estructura y el mismo valor para mesa directiva), cercanía $(0,66$ y 0,33$)$ o disparidad (1 y 0,33). Mientras que las dos primeras situaciones no impiden clasificar a los casos como un modelo de difusión o penetración territorial según corresponda, la disparidad muestra casos híbridos. 


\section{El universo de análisis: las estrategias de competencia electoral}

Tal como precisé en el apartado metodológico anterior, el grado de acuerdo multinivel está asociado al modelo de construcción definido por los actores que conformaron las distintas coaliciones entre 1995 y 2015 en Argentina. Cada una de estas coaliciones privilegió una estrategia electoral específica en cada distrito, y el resultado agregado de los 24 distritos permite caracterizar a cada uno de los casos siguiendo los criterios antes definidos. Pero antes de avanzar en la clasificación de los 25 casos estudiados, primero resumo la variabilidad de las estrategias electorales definidas durante el período estudiado en el Gráfico 3.

\section{GRÁFICO 3}

Estrategias electorales definidas

para las 25 coaliciones electorales multinivel, 1995-2015

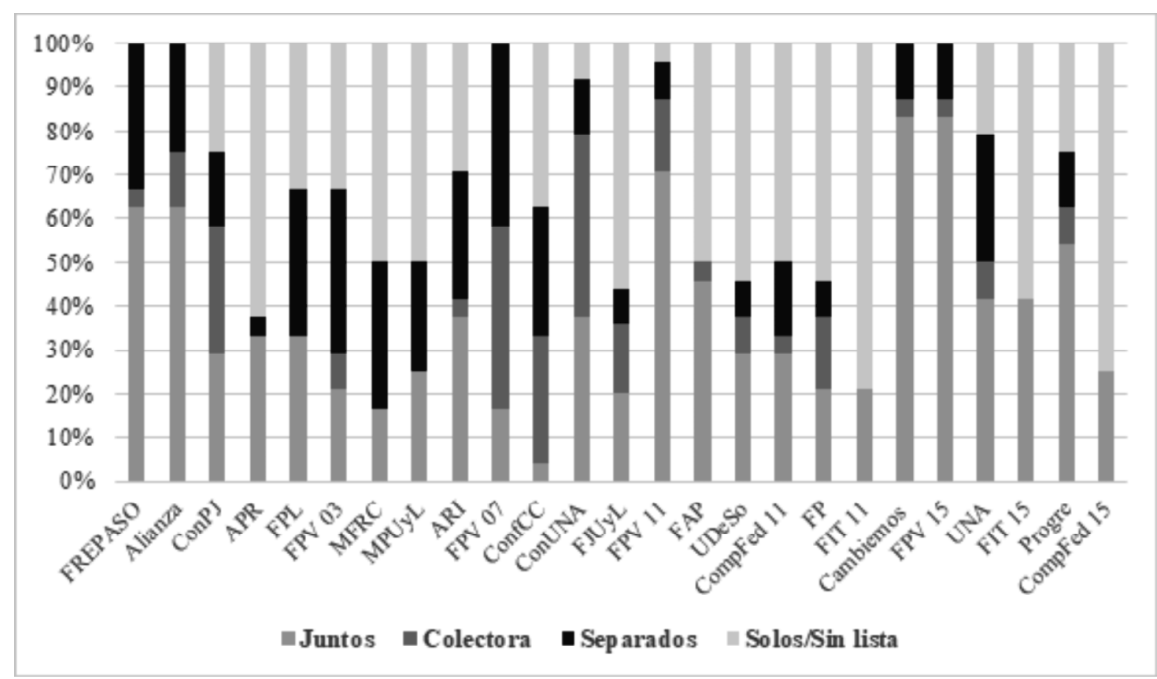

Fuente: Elaboración propia en base a datos provistos por Cámara Nacional Electoral, Atlas Electoral Andy Tow y medios periodísticos provinciales.

Tal como se desprende de los datos, las coaliciones electorales multinivel definieron distintas estrategias electorales en cada provincia del país. A pesar de la diversidad, puedo ordenar los casos en determinados grupos con ciertas características comunes ${ }^{9}$. Primero, las coaliciones peronistas son to-

Con esto solo busco sumar información relevante, la cual no incide en la asociación entre variables. 
das aquellas que incluyeron al Partido Justicialista y otros partidos menores en su interior. Salvo por la atípica elección presidencial del año 2003, en las restantes elecciones en más de la mitad de los distritos todos o algunos de los partidos que integraron la coalición electoral presidencial formaron parte de las coaliciones electorales legislativas. Segundo, las coaliciones radicales ${ }^{10}$ tuvieron mayores dificultades para alcanzar acuerdos electorales sólidos y extendidos en el territorio nacional. Dejando de lado las experiencias de la Alianza y de Cambiemos, esto va en línea con el impacto negativo que tuvo la crisis del año 2001 en la marcada desnacionalización del sistema partidario argentino (Calvo y Escolar, 2005; Leiras, 2007; Varetto, 2017). Un tercer grupo de coaliciones pueden ser denominadas como «nuevos actores partidarios»: estos fueron acuerdos electorales entre partidos políticos que surgieron en el sistema partidario argentino desde la Reforma Constitucional de 1994 en adelante. Me refiero a las coaliciones que construyeron Acción por la República (APR), Recrear, $\mathrm{ARI}^{11}$ y GEN ${ }^{12}$. Todos estos casos muestran que hubo dificultades para que las elites partidarias replicaran acuerdos electorales en la mayoría de los distritos, lo cual motivó que estos nuevos partidos tuvieran que competir solos para el cargo de diputados nacionales en gran parte del territorio nacional. En parte, tal vez, porque esos acuerdos fueron construidos por actores partidarios que eran desprendimientos de los partidos tradicionales, con base metropolitana en la Ciudad de Buenos Aires, Provincia de Buenos Aires y Santa Fe, y con un liderazgo nacional muy marcado. Sus aliados, en la mayoría de los casos, fueron otros partidos menores, radicados en unos pocos distritos del interior del país y

10 Es el calificativo asignado a dirigentes, militantes y acuerdos formados por la Unión Cívica Radical (UCR). Para mayor detalle sobre sus características y particularidades, recomiendo Zelaznik (2013). El más clásico es Rock (1977).

11 Acción Por la República (APR) fue creado por el ex Ministro de Economía (19911996) Domingo Cavallo. Recrear para el Crecimiento fue una fuerza liderada por el ex Ministro de Defensa (1999-2001), ex Ministro de Economía (2001) y dirigente radical de la Provincia de Buenos Aires, Ricardo López Murphy. Afirmación para Una República Igualitaria (ARI) fue creado por la también ex Diputada radical Elisa Carrió. Actualmente se denomina Coalición Cívica-ARI (CC-ARI) y forma parte del gobierno de coalición de Cambiemos. Es el único que ha alcanzado cierto grado de institucionalización con posterioridad al 2001 y hasta la fecha. Para un análisis detallado del primero recomiendo Leiras (2007), mientras que para los dos restantes se puede consultar Colombram y Cruz (2013).

12 El Partido Generación para un Encuentro Nacional (GEN) surgió entre finales del 2006 y comienzos del 2007 luego de desprenderse de la UCR cuando se estaba formando ConUNA. Los dirigentes que impulsaron el desprendimiento fueron Margarita Stolbizer -Secretaria Nacional de la UCR-, Jaime Linares, Horacio Alcuaz y Gerardo Milman, todos ellos provenientes de la UCR de la Provincia de Buenos Aires. Esta nota al pie y la anterior son ejemplos claros de la facilidad existente en el sistema político argentino para crear partidos. 
con menor proyección nacional que los mencionados. Algo similar ocurre con el cuarto grupo: las coaliciones peronistas disidentes que surgieron de un distrito concreto. Son el Frente Justicia, Unión y Libertad, el Movimiento Popular Unión y Libertad (MPUyL), Compromiso Federal (2011 y 2015) ${ }^{13}$, el Frente Popular ${ }^{14}$ y Unión por una Nueva Alternativa (UNA 15) ${ }^{15}$. Todos ellos, casos de dirigentes partidarios peronistas que enfrentaron al oficialismo de turno: en la mayoría de los casos al Frente para la Victoria (FPV).

Independientemente de las caracterizaciones realizadas, me quiero concentrar en la correlación entre el modelo de construcción coalicional y el grado de acuerdo multinivel alcanzado. En la siguiente tabla procedo a clasificar cada uno de los 25 casos estudiados según el grado de acuerdo multinivel alcanzado.

Según los datos expuestos, hay mayoría de coaliciones electorales (64\%) cuyo grado de acuerdo multinivel tendió a ser medio-bajo (2 casos) o bajo (14 casos). Esto muestra que el proceso de formación de estas construcciones políticas tiene un sinnúmero de dificultades y factores que impactan en el resultado final. Es una tendencia propia del sistema político argentino y particularmente notoria en los 20 años que cubre este trabajo. Tal como mencioné anteriormente, las posibilidades que brinda el régimen legal electoral dejan a las elites partidarias provinciales la potestad de definir la estrategia electoral que mejor corresponda con sus intereses locales o provinciales, dificultando la integración entre los socios de un acuerdo. Este punto coincide con la literatura especializada sobre el tema (Calvo y Escolar, 2005; Leiras, 2007; Escolar, 2014; Clerici, 2015).

13 FJUyL, MPUyL y Compromiso Federal (2011 y 2015) fueron las coaliciones electorales multinivel que construyeron los hermanos Rodríguez Saá, Adolfo y Alberto, ambos gobernadores de San Luis en distintos períodos. Desde ese distrito se alternaron el salto al nivel nacional y construyeron sus acuerdos con partidos menores que le dieron presencia en algunos distritos a los cuales les costaba hacer pie. A partir del año 2011, el partido nacional Es Posible se convirtió en la estructura política central sobre la cual conformaron estos acuerdos.

14 El Frente Popular fue la coalición electoral multinivel que llevó como candidato presidencial a Eduardo Duhalde en el año 2011, acompañado por Mario Das Neves. Estuvo conformada por el histórico partido peronista Unión Popular (fundado en 1955), junto a otros también históricos partidos menores de la Argentina (MID, Partido Demócrata Cristiano y Partido Autonomista) y varios partidos de distrito.

15 UNA fue continuación del Frente Renovador liderado por Sergio Massa, acuerdo que se presentó en la Provincia de Buenos Aires en el 2013. Para el año 2015, amplió el acuerdo a otros sectores peronistas disidentes, concentrados geográficamente en las provincias de Córdoba, y en el noreste y noroeste del país. 


\section{Facundo Cruz}

\section{TABLA 2}

Tipo de acuerdo electoral para coaliciones electorales multinivel, 1995-2015

\begin{tabular}{|c|c|c|c|}
\hline Año & Caso & Sigla & $\begin{array}{c}\text { Clasificación del caso } \\
\text { (grado de acuerdo multinivel) }\end{array}$ \\
\hline 1995 & FREPASO & FREPASO & Coalición articulada (alto) \\
\hline 1999 & $\begin{array}{c}\text { Alianza Para el Trabajo, la Justicia } \\
\text { y la Educación }\end{array}$ & Alianza & Coalición articulada (alto) \\
\hline 1999 & $\begin{array}{c}\text { Alianza Concertación Justicialista } \\
\text { para el Cambio }\end{array}$ & ConPJ & Coalición acoplada (medio-alto) \\
\hline 1999 & Alianza Acción por la República & APR & Coalición desconectada (bajo) \\
\hline 2003 & Alianza Frente por la Lealtad & FPL & Coalición desconectada (bajo) \\
\hline 2003 & Alianza Frente para la Victoria & FPV 03 & Coalición descoordinada (medio-bajo) \\
\hline 2003 & $\begin{array}{l}\text { Alianza Movimiento Federal } \\
\text { para Recrear el Crecimiento }\end{array}$ & MFRC & Coalición desconectada (bajo) \\
\hline 2003 & $\begin{array}{c}\text { Alianza Movimiento Popular Unión } \\
\text { y Libertad }\end{array}$ & MPUyL & Coalición desconectada (bajo) \\
\hline 2003 & $\begin{array}{c}\text { Alianza Afirmación } \\
\text { por una República Igualitaria }\end{array}$ & ARI & Coalición desconectada (bajo) \\
\hline 2007 & Alianza Frente para la Victoria & FPV 07 & Coalición acoplada (medio-alto) \\
\hline 2007 & Alianza Confederación Coalición Cívica & ConfCC & Coalición desconectada (bajo) \\
\hline 2007 & $\begin{array}{l}\text { Alianza Concertación } \\
\text { Una Nación Avanzada }\end{array}$ & ConUNA & Coalición acoplada (medio-alto) \\
\hline 2007 & Alianza Frente Justicia, Unión y Libertad & FJUyL & Coalición desconectada (bajo) \\
\hline 2011 & Alianza Frente para la Victoria & FPV 11 & Coalición articulada (alto) \\
\hline 2011 & Alianza Frente Amplio Progresista & FAP & Coalición desconectada (bajo) \\
\hline 2011 & Alianza Unión para el Desarrollo Social & UDeSo & Coalición desconectada (bajo) \\
\hline 2011 & Alianza Compromiso Federal & CompFed 11 & Coalición desconectada (bajo) \\
\hline 2011 & Alianza Frente Popular & FP & Coalición desconectada (bajo) \\
\hline 2011 & $\begin{array}{c}\text { Alianza Frente de Izquierda } \\
\text { y de los Trabajadores }\end{array}$ & FIT 11 & Coalición desconectada (bajo) \\
\hline 2015 & Alianza Cambiemos & Cambiemos & Coalición articulada (alto) \\
\hline 2015 & Alianza Frente para la Victoria & FPV 15 & Coalición articulada (alto) \\
\hline 2015 & $\begin{array}{c}\text { Alianza Unidos por } \\
\text { Una Nueva Alternativa }\end{array}$ & UNA & Coalición descoordinada (medio-bajo) \\
\hline 2015 & $\begin{array}{c}\text { Alianza Frente de Izquierda } \\
\text { y de los Trabajadores }\end{array}$ & FIT 15 & Coalición desconectada (bajo) \\
\hline 2015 & Alianza Progre sistas & Progre & Coalición articulada (alto) \\
\hline 2015 & Alianza Compromiso Federal & CompFed 15 & Coalición desconectada (bajo) \\
\hline
\end{tabular}

Fuente: Elaboración propia. 
Los 25 casos pueden ser agrupados de la siguiente manera.

\section{TABLA 3}

Tabla resumen clasificación de los casos según grado de acuerdo multinivel. Argentina, 1995-2015.

\begin{tabular}{|c|c|c|}
\hline Clasificación del caso & Cantidad & Grado de acuerdo multinivel alcanzado \\
\hline Coalición articulada & 6 & Grado alto de acuerdo multinivel \\
\hline Coalición acoplada & 3 & Grado medio-alto de acuerdo multinivel \\
\hline Coalición descoordinada & 2 & Grado medio-bajo de acuerdo multinivel \\
\hline Coalición desconectada & 14 & Grado bajo de acuerdo multinivel \\
\hline
\end{tabular}

Fuente: Elaboración propia.

\section{La relación entre el modelo de construcción coalicional y el grado de acuerdo multinivel alcanzado}

Ahora bien, ¿̇en qué medida el modelo de construcción coalicional está asociado a grados variables de acuerdo multinivel? Tal como mencioné anteriormente, la mesa directiva y la estructura política con la que las elites partidarias arman la coalición me permiten clasificar a los casos según un modelo de difusión territorial o de penetración territorial. En la siguiente tabla especifico este punto según las reglas expuestas en el apartado metodológico.

En un panorama general, existe cierta correlación entre las variables. Las coaliciones que se formaron siguiendo el modelo de difusión territorial alcanzaron grados de acuerdo multinivel alto o medio alto (9 de los 13 casos, $69 \%$ del total). En contraposición, en todos los casos donde las elites partidarias que privilegiaron la formación de sus coaliciones por penetración territorial se logaron grados medio-bajos o bajos (100\% de los casos). Solamente 4 casos son híbridos (MFRC, ARI, FIT 11 y FIT 15). Los cuales, a su vez, se suman al grupo acuerdos partidarios de bajo grado: son todos casos clasificados como desconectados. 


\section{TABLA 4}

\section{Clasificación de los 25 casos según su mesa directiva, su estructura política y su modelo de construcción coalicional}

\begin{tabular}{|c|c|c|c|c|}
\hline Año & Caso & Mesa Directiva & Estructura Política & $\begin{array}{c}\text { Modelo de } \\
\text { Construcción }\end{array}$ \\
\hline 1995 & FREPASO & Balanceada (1) & Extendida (1) & Difusión territorial \\
\hline 1999 & Alianza & $\begin{array}{l}\text { Levemente balanceada } \\
\qquad(0,66)\end{array}$ & Extendida (1) & Difusión territorial \\
\hline 1999 & ConPJ & Balanceada (1) & $\begin{array}{l}\text { Levemente extendida } \\
(0,66)\end{array}$ & Difusión territorial \\
\hline 1999 & APR & $\begin{array}{l}\text { Levemente balanceada } \\
\qquad(0,66)\end{array}$ & $\begin{array}{c}\text { Levemente concentrada } \\
(0,33)\end{array}$ & $\begin{array}{c}\text { Penetración } \\
\text { territorial }\end{array}$ \\
\hline 2003 & FPL & Balanceada (1) & Extendida (1) & Difusión territorial \\
\hline 2003 & FPV 03 & Balanceada (1) & $\begin{array}{l}\text { Levemente extendida } \\
(0,66)\end{array}$ & Difusión territorial \\
\hline 2003 & MFRC & Balanceada (1) & $\begin{array}{c}\text { Levemente concentrada } \\
(0,33)\end{array}$ & Caso híbrido \\
\hline 2003 & MPUyL & $\begin{array}{c}\text { Levemente desbalanceada } \\
(0,33)\end{array}$ & $\begin{array}{c}\text { Levemente concentrada } \\
(0,33)\end{array}$ & $\begin{array}{c}\text { Penetración } \\
\text { territorial }\end{array}$ \\
\hline 2003 & ARI & $\begin{array}{c}\text { Levemente desbalanceada } \\
(0,33)\end{array}$ & Extendida (1) & Caso híbrido \\
\hline 2007 & FPV 07 & Balanceada (1) & Extendida (1) & Difusión territorial \\
\hline 2007 & ConfCC & $\begin{array}{l}\text { Levemente balanceada } \\
\qquad(0,66)\end{array}$ & Extendida (1) & Difusión territorial \\
\hline 2007 & ConUNA & Balanceada (1) & Extendida (1) & Difusión territorial \\
\hline 2007 & FJUyL & $\begin{array}{c}\text { Levemente desbalanceada } \\
(0,33)\end{array}$ & $\begin{array}{c}\text { Levemente concentrada } \\
(0,33)\end{array}$ & $\begin{array}{c}\text { Penetración } \\
\text { territorial }\end{array}$ \\
\hline 2011 & FPV 11 & $\begin{array}{l}\text { Levemente balanceada } \\
\qquad(0,66)\end{array}$ & Extendida (1) & Difusión territorial \\
\hline 2011 & FAP & $\begin{array}{c}\text { Levemente balanceada } \\
(0,66)\end{array}$ & $\begin{array}{c}\text { Levemente extendida } \\
(0,66) \\
\end{array}$ & Difusión territorial \\
\hline 2011 & UDeSo & $\begin{array}{c}\text { Levemente desbalanceada } \\
(0,33)\end{array}$ & $\begin{array}{c}\text { Levemente concentrada } \\
(0,33)\end{array}$ & $\begin{array}{c}\text { Penetración } \\
\text { territorial }\end{array}$ \\
\hline 2011 & $\begin{array}{c}\text { CompFed } \\
11 \\
\end{array}$ & $\begin{array}{c}\text { Levemente desbalanceada } \\
(0,33)\end{array}$ & $\begin{array}{c}\text { Levemente concentrada } \\
(0,33) \\
\end{array}$ & $\begin{array}{c}\text { Penetración } \\
\text { territorial }\end{array}$ \\
\hline 2011 & FP & $\begin{array}{c}\text { Levemente balanceada } \\
(0,66)\end{array}$ & $\begin{array}{c}\text { Levemente concentrada } \\
(0,33)\end{array}$ & $\begin{array}{c}\text { Penetración } \\
\text { territorial }\end{array}$ \\
\hline 2011 & FIT 11 & Balanceada (1) & $\begin{array}{c}\text { Levemente concentrada } \\
(0,33)\end{array}$ & Caso híbrido \\
\hline 2015 & Cambiemos & $\begin{array}{l}\text { Levemente balanceada } \\
\qquad(0,66)\end{array}$ & Extendida (1) & Difusión territorial \\
\hline 2015 & FPV 15 & Balanceada (1) & Extendida (1) & Difusión territorial \\
\hline 2015 & UNA & Desbalanceada (0) & $\begin{array}{c}\text { Levemente concentrada } \\
(0,33)\end{array}$ & $\begin{array}{c}\text { Penetración } \\
\text { territorial }\end{array}$ \\
\hline 2015 & FIT 15 & Balanceada (1) & $\begin{array}{c}\text { Levemente concentrada } \\
(0,33) \\
\end{array}$ & Caso híbrido \\
\hline 2015 & Progre & $\begin{array}{l}\text { Levemente balanceada } \\
\qquad(0,66)\end{array}$ & Extendida (1) & Difusión territorial \\
\hline 2015 & $\begin{array}{c}\text { CompFed } \\
15\end{array}$ & $\begin{array}{c}\text { Levemente desbalanceada } \\
(0,33)\end{array}$ & $\begin{array}{c}\text { Levemente concentrada } \\
(0,33)\end{array}$ & $\begin{array}{c}\text { Penetración } \\
\text { territorial }\end{array}$ \\
\hline
\end{tabular}

Fuente: Elaboración propia. 
Cada uno de estos casos alcanzó un determinado grado de acuerdo multinivel entre las elites partidarias que impulsaron el acercamiento. Al cruzar la Tabla $\mathrm{N}^{\circ} 2$ con la $\mathrm{N}^{\circ} 4$ se puede apreciar la asociación entre ambas variables.

\section{TABLA 5}

Grado de acuerdo multinivel

\begin{tabular}{|c|c|c|c|c|c|}
\hline $\begin{array}{c}\text { Grado de } \\
\text { acuerdo } \\
\text { multinivel }\end{array}$ & $\begin{array}{l}\text { Clasificación } \\
\text { del caso }\end{array}$ & Difusión territorial & $\begin{array}{c}\text { Penetración } \\
\text { territorial }\end{array}$ & $\begin{array}{c}\text { Casos } \\
\text { híbridos }\end{array}$ & $\mathbf{N}$ \\
\hline Alto & $\begin{array}{c}\text { Coalición } \\
\text { articulada }\end{array}$ & $\begin{array}{c}\text { FEPASO } \\
\text { Alianza } \\
\text { FPV } 11 \\
\text { Cambiemos } \\
\text { FPV 15 } \\
\text { Progre }\end{array}$ & & & 6 \\
\hline Medio-Alto & $\begin{array}{l}\text { Coalición } \\
\text { acoplada }\end{array}$ & $\begin{array}{c}\text { ConPJ } \\
\text { FPV 07 } \\
\text { ConUNA }\end{array}$ & & & 3 \\
\hline $\begin{array}{l}\text { Medio- } \\
\text { Bajo }\end{array}$ & $\begin{array}{c}\text { Coalición } \\
\text { descoordinada }\end{array}$ & FPV 03 & UNA & & 2 \\
\hline Bajo & $\begin{array}{c}\text { Coalición } \\
\text { desconectada }\end{array}$ & $\begin{array}{c}\text { ConfCC } \\
\text { FAP } \\
\text { FPL }\end{array}$ & $\begin{array}{c}\text { APR } \\
\text { MPUyL } \\
\text { FJUyL } \\
\text { UDeSo } \\
\text { CompFed } 11 \\
\text { FP } \\
\text { CompFed 15 }\end{array}$ & $\begin{array}{l}\text { MFRC } \\
\text { ARI } \\
\text { FIT } 11 \\
\text { FIT } 15\end{array}$ & 14 \\
\hline \multicolumn{2}{|r|}{$\mathbf{N}$} & 13 & 8 & 4 & 25 \\
\hline
\end{tabular}

\begin{tabular}{|c|c|c|c|c|}
\hline Grado de acuerdo multinivel & Difusión territorial & $\begin{array}{c}\text { Penetración } \\
\text { territorial }\end{array}$ & $\begin{array}{c}\text { Casos } \\
\text { híbridos }\end{array}$ & $\mathbf{N}$ \\
\hline $\begin{array}{c}\text { Alto } \\
\text { Medio-Alto }\end{array}$ & $69 \%$ & $0 \%$ & $0 \%$ & $\mathbf{9}$ \\
$\begin{array}{c}\text { Medio-Bajo } \\
\text { Bajo }\end{array}$ & $31 \%$ & $100 \%$ & $100 \%$ & $\mathbf{1 6}$ \\
\hline N & $\mathbf{1 3}$ & $\mathbf{8}$ & $\mathbf{4}$ & $\mathbf{2 5}$ \\
\hline
\end{tabular}

Fuente: Elaboración propia.

Adicionalmente, pueden incluirse algunos hallazgos que merecen ser destacados ${ }^{16}$. La asociación entre el modelo de construcción coalicional y el grado de acuerdo alcanzado por las elites partidarias guarda relación con la

16 Si bien la discusión empírica desarrollada a continuación incluye variables que no son tenidas en cuenta en este trabajo, éstas formaron parte de una investigación doctoral previa de la cual se desprende este trabajo (Cruz 2018). Resultará útil para un segundo trabajo en desarrollo que incluye a todas las variables dentro de un modelo de QCA (Qualitative Comparative Analysis) fuzzy sets donde se busque encontrar una relación de causalidad entre variables. 
distribución de los casos en cuatro grupos que realicé en el apartado anterior. La mayoría de las coaliciones peronistas siguieron un modelo de construcción por difusión territorial. Este hallazgo está matizado por un elemento no menor en el período estudiado en este trabajo: de los 20 años que transcurrieron entre 1995 y 2015, en 18 años el peronismo ocupó el rol de oficialismo nacional. Las coaliciones del Partido Justicialista (Con PJ 1999 y FPV 2007, 2011 y 2015) alcanzaron un grado alto o medio-alto de acuerdo multinivel mientras fueron los ocupantes de Balcarce 50. El peso de ser oficialismo nacional puede ser un factor relevante de impacto: el oficialismo ordenó los acuerdos electorales multinivel, especialmente en lo que respecta a las listas de diputados nacionales. Al menos, en el caso del peronismo.

Este escenario presenta matices complejos en las elecciones del año 2003. En ese momento, el peronismo se presentó fragmentado en tres coaliciones electorales multinivel distintas, con una menor proporción de distritos donde alcanzó acuerdos integrados y en un escenario de inestabilidad política, social, económica e institucional como el que caracterizó el período con posterioridad a la salida de la Alianza del gobierno nacional. Parte de esa inestabilidad se materializó en el calendario electoral para diputados nacionales más desdoblado de todo el período estudiado: solamente 2 de 24 provincias fueron concurrentes con las elecciones presidenciales del 27 de abril de 2003. No es casual, entonces, que, saliendo de una etapa de crisis muy marcada, habiendo ocupado el rol de oposición nacional entre 1999 y 2001, y con un liderazgo nacional disputado entre tres actores centrales (Néstor Kirchner —FPV 2003—, Carlos Menem —FPL—y Adolfo Rodríguez Saá —MPUyL—) ${ }^{17}$, el impacto sobre el grado de acuerdo multinivel haya sido muy grande: las coaliciones peronistas del 2003 estuvieron desconectadas. Y también donde menos clara es la asociación entre las variables: FPV y FPL fueron construcción por difusión, mientras que MPUyL fue por penetración territorial.

Los casos de coaliciones electorales multinivel no peronistas, en cambio, presentaron pequeñas diferencias que las distinguen de las anteriores pero que mantienen igual patrones comunes de construcción. Me refiero a FREPASO en 1995, la Alianza 1999, ConUNA en 2007, Cambiemos y Progresistas en $2015^{18}$. Todos estos fueron casos que se presentaron como fé-

17 En ese momento ejercía la Presidencia de la Nación Eduardo Duhalde, designado por la Asamblea Legislativa el 2 de enero del 2002 para culminar el mandato dejado vacante por Fernando De La Rúa (Alianza-UCR) luego de su renuncia. Mantuvo una fuerte disputa por el control del PJ con Carlos Menem y con Adolfo Rodríguez Saá. Esa tensión interna fue saldada en las elecciones presidenciales del año 2003 : cada uno de estos últimos con su coalición electoral, y Duhalde apoyando al FPV.

18 Solo quedan fuera de este grupo FAP, formada por el Partido Socialista y otros aliados, y Unión para el Desarrollo Social, integrada por la Unión Cívica Radical y un grupo de partidos peronistas disidentes del oficialismo Frente para la Victoria. 
rreos competidores del oficialismo de turno, aunque no en todos ellos los resultados electorales hayan sido los esperados por sus dirigentes. Como puntos en común, todas estas coaliciones presentaron grados de acuerdo multinivel altos o medios altos: mientras que caractericé a ConUNA como una coalición acoplada, todas las restantes fueron coaliciones integradas. Salvo pequeñas diferencias, todas las mencionadas presentaron estructuras políticas bien distribuidas en el territorio y mesas directivas balanceadas en términos de su representación territorial. Sin embargo, lo más destacado y que se contrapone al caso de las coaliciones formadas por el peronismo es que estos cinco casos se formaron en la oposición al gobierno nacional. Motivo por el cual, si al Partido Justicialista le resultó útil ocupar el Sillón de Rivadavia para ordenar a la tropa, en el caso de los dirigentes no peronistas los acuerdos se alcanzaron a pesar de estar fuera de la Casa Rosada y de ir cambiando su morfología interna ${ }^{19}$.

La última regularidad que quiero destacar es en tres agrupamientos de casos distintos: las coaliciones peronistas disidentes (MPUyL, FJUyL, CompFed 11 y 15, FP y UNA), las formadas por nuevos actores partidarios (APR, ARI y MFRC) y las integradas por partidos trotskistas (FIT 11 y 15). Los primeros refuerzan la asociación entre el modelo de construcción por penetración territorial y un bajo grado de acuerdo multinivel. Valga la redundancia, los dirigentes que impulsaron estas coaliciones lo hicieron desde distritos específicos del país aprovechando los recursos políticos provistos por una gobernación (San Luis en el caso de MPUyL, FJUyL, y CompFed 11 y 15) o bien cierto grado de desarrollo político concentrado en una provincia (Buenos Aires para UNA y $\mathrm{FP}^{20}$ ). Desde estos bastiones electorales, fue que un conjunto reducido de dirigentes peronistas disidentes con estructuras partidarias propias y un grupo acotado de aliados nacionales con escaso peso electoral, intentaron competir contra el oficialismo de turno: el Frente para la Victoria. En lo que respecta a los dos agrupamientos restantes, salvo el caso de APR, todas las demás coaliciones entran dentro de los casos híbridos. Esto es, o bien conformaron una estructura política extendida en el territorio, y una mesa directiva balanceada y concentrada (ARI), o viceversa (MFRC, FIT 11 y 15). Cualquiera sea el caso, en ambos grupos son notorias las dificultades que tuvieron sus dirigentes para lograr un alto grado de acuerdo multinivel en un escenario de desnacionalización partidaria sostenido con posterioridad al 2001 (Calvo y Escolar, 2005; Varetto, 2017).

19 Solo el Frente Amplio Progresista (2011) y Progresistas (2015) estuvieron formadas por los mismos partidos políticos. Los restantes casos fueron cambiando en su composición interna.

20 El otro distrito de apoyo de esta coalición fue la provincia de Chubut. Esto se materializó en la fórmula presidencial Eduardo Duhalde (Buenos Aires) - Mario Das Neves (Chubut). 


\section{Conclusiones}

El objetivo de este artículo se centró en explorar la asociación entre el modelo de construcción coalicional y el grado de acuerdo multinivel alcanzado por las elites partidarias que los impulsaron. Tal como indiqué, forma parte de un proyecto de investigación más amplio que exploró sobre el proceso de construcción de las coaliciones electorales en un escenario de desnacionalización partidaria sostenida. Estos acuerdos se presentan como una fórmula política privilegiada en este tipo de escenarios, más aún cuando la dinámica competitiva adquiere componentes multinivel muy marcados. En este sentido, es posible que las coaliciones electorales hayan llegado a Argentina y se queden un buen tiempo entre nosotros. Tal como indicaron Clerici y Scherlis (2014), el marco legal argentino deja un margen de acción muy amplio para que las elites partidarias conformen distintos tipos de acuerdos. Resulta clave indagar sobre las decisiones estratégicas de los propios dirigentes. Éstas pueden ser operacionalizadas y medidas de acuerdo a determinadas pautas y reglas claras.

Entre los principales hallazgos, puedo sintetizar que existe cierta correlación entre las variables desarrolladas. Si bien la asociación es más fuerte entre el modelo de penetración territorial y un bajo grado de acuerdo multinivel (100\% de los casos identificados), uno puede considerar que las coaliciones que se forman por difusión territorial tienden a lograr mayores grados de acuerdo (67\%). La cantidad de casos que no siguen lo propuesto en el marco teórico (4 en total) representan menos de la mitad de los casos que se clasifican como difusión (31\%) y son una baja proporción sobre el total de la población (16\%). Aquellas coaliciones presentadas como híbridas (4 casos) tampoco debilitan la relación planteada.

Este trabajo deja abierta una agenda de investigación en dos líneas posibles. En primer lugar, profundizar los casos estudiados a partir de la configuración de condiciones causales que produzcan un determinado fenómeno. Esto es, cuál es la combinación de condiciones que favorecen o perjudican grados de acuerdo multinivel altos. Para ello, resulta conveniente avanzar hacia el método cualitativo comparado (QCA). En segundo lugar, precisar sobre casos específicos que presenten modelos contrapuestos de construcción y lleguen a resultados también diferentes. Para ello, resultará necesario aplicar el método configuracional comparado junto al processtracing $^{21}$. Porque, en definitiva, el estudio de las coaliciones, sus tipos y sus procesos formativos aún deja tela para cortar en América Latina.

21 Ambas propuestas están siendo desarrolladas en el marco del proyecto de investigación mencionado. 


\section{Referencias bibliográficas}

Calvo, E. y M. Escolar (2005). La nueva política de partidos en la Argentina. Crisis política, realineamientos partidarios y reforma electoral. Buenos Aires: Prometeo - PENT.

Carroll, R. A. (2007). The Electoral Origins of Governing Coalitions. [Tesis Doctoral sin publicar, University of California.]

Chasquetti, D. (2008). Democracia, presidencialismo y partidos políticos en América Latina: Evaluando la «difícil combinación». Montevideo: Ediciones CAUCE, Facultad de Ciencias Sociales (Universidad de la República, Uruguay) y Comisión Sectorial de Investigación Científica.

Clerici, P. (2014). Aliados y Contendientes. Dimensionando el Fenómeno de la Congruencia Aliancista en Argentina (1983-2013). [Tesis doctoral, Universidad Torcuato Di Tella.]

Clerici, P. (2015). La creciente importancia de las alianzas electorales en un escenario de competencia territorializada. El caso argentino. En Revista SAAP 9 (2), 313-341.

Clerici, P. (2018). La influencia de la dicotomía oficialismo/oposición sobre la congruencia de las coaliciones electorales en Argentina. En Revista POSTData 23 (1), 121-149.

Clerici, P, F. Cruz, L. Goyburu, N. Skigin, I. Seira, A. Albala y A. Molina (2016). Coaliciones políticas en América Latina. En Revista Iberoamericana XVI (61), 237266.

Clerici, P. y G. Scherlis (2014). La Regulación de Alianzas Electorales y sus Consecuencias en Sistemas Multi-nivel en América Latina. En Revista del Instituto de Investigaciones Jurídicas y Sociales Ambrosio L. Gioja VIII (12), 79-98.

Colombram, J y F. Cruz (2013). 'Partidos porteños': nacimiento, auge y ¿crisis? de CC-ARI, RECREAR y CPC-PRO en la Argentina post 2001. Trabajo presentado en XI Congreso Nacional de Ciencia Política, Sociedad Argentina de Análisis Político (SAAP), Paraná, Entre Ríos, 17 al 20 de julio.

Cox, G. W. (2000). Electoral Coordination. En International Encyclopedia of Elections, editado por Richard Rose. Londres: MacMillan.

Cruz, F. (2014). ¿Socios de menor nivel? Aportes para el estudio de las coaliciones subnacionales en sistemas políticos multinivel. En Revista Uruguaya de Ciencia Política 23 (1): 11-39.

Cruz, F. (2018). Construyendo House of Cards. Partidos y coaliciones en la Argentina, 19952015. [Tesis de Doctorado, Escuela de Política y Gobierno, Universidad Nacional de San Martín. Disponible en https://www.academia. edu/36238712/ Construyendo_House_of_Cards._Partidos_y_coaliciones_en_Argentina_19952015.]

Cruz, F. (2019a). Construcción de coaliciones electorales en escenarios desnacionalizados. Un aporte teórico. En Revista de Estudios Políticos 184, 161-194.

Cruz, F. (2019b). Socios, pero no tanto. Partidos y coaliciones en la Argentina, 2003-2015. Buenos Aires: Eudeba. 
De Luca, M., M. P. Jones y M. I. Tula (2002). Back Rooms or Ballot Boxes? Candidate Nomination in Argentina. En Comparative Political Studies 35 (4), 413-436.

De Luca, M., M. P. Jones y M. I. Tula. (2008). Revisando las consecuencias políticas de las primarias. Un estudio sobre las elecciones de gobernador en la Argentina. En Revista POSTData 13, 81-102.

Devoto, L. M. y Juan C. Olmeda. (2017). Juntos pero revueltos. Estrategias electorales y coaliciones partidarias para la elección de diputados locales en los estados mexicanos (2000-2016). En Revista Colombia Internacional 90 (abril-junio), 157187.

Došek, T. y F. Freidenberg. (2013). La congruencia de los partidos y los sistemas de partidos multinivel en América Latina: conceptualización y evaluación de algunas herramientas de medición. En Politai: Revista de Ciencia Política 4 (7), 161-178.

Downs, W. M. (1998). Coalition Government, Subnational Style - Multiparty Politics in European Regional Parliaments. Columbus: Ohio State University Press.

Escolar, M. (2014). Juntos pero no revueltos. Segmentación estratégica y coaliciones efímeras. En Escolar, M. y J. M. Abal Medina (Coords.), Modus Vivendi. Política Multinivel y Estado Federal en Argentina. Buenos Aires: Prometeo.

Falleti, T. G. y J. Lynch (2009). Context and Causation in Political Analysis. En Comparative Political Studies 49 (9), 1143-1166.

George, A. y A. Bennett (2005). Case Studies and the Development of Theory. Cambridge: The MIT Press.

Gervasoni, C. (2012). La política provincial es política nacional: cambios y continuidades subnacionales del menemismo al kirchnerismo. En Malamud, Ay M. De Luca (Coords.), La Política en Tiempos de los Kirchner. Buenos Aires: Eudeba

Goertz, G. y J. Mahoney (2012). A Tale of Two Cultures: Qualitative and Quantitative Research in the Social Sciences. Princeton: Princeton University Press.

Machado, C. (2017). Coligações revisitadas: metodologias e encruzilhadas. En Krause, S., C. Machado, L. F. Miguel (Coords.), Coligações e disputas eleitorais na Nova República: aportes teórico-metodológicos, tendências e estudos de caso. San Pablo: UNESP, Fundação Konrad Adenauer.

Leiras, M. (2007). Todos los caballos del rey. La integración de los partidos políticos y el gobierno democrático en la Argentina, 1995-2003. Buenos Aires: Prometeo.

Lodola, G. (2012). Gobierno nacional, gobernadores e intendentes en el período kirchnerista. En En Malamud, Ay M. De Luca (Coords.), La Política en Tiempos de los Kirchner. Buenos Aires: Eudeba.

Mauro, S. (2008). Coalition Politics in a Federalized Party System: The Case of Argentina. En Albala, A. y Reniú, J. M. (Eds.), Coalition Politics and Federalism. Springer.

Mahoney, J. (2001). Beyond Correlational Analysis: Recent Innovations in Theory and Method. En Sociological Forum 16 (3), 575-93.

Mahoney, J. (2001). Beyond Correlational Analysis: Recent Innovations in Theory and Method. En Sociological Forum 16 (3), 575-93. 
Mair, P. y R. Katz (1995). Changing Models of Party Organization and Party Democracy: The Emergence of the Cartel Party. En Party Politics 1 (1), 5-27.

Méndez de Hoyos, I. (2012). Coaliciones preelectorales y competencia partidista en México a nivel federal y local (1994-2011). En Politica y gobierno XIX (2), 147198.

Miño, J. A (2014). El efecto del gobierno dividido vertical sobre la formación de alianzas divergentes en los estados mexicanos, 1994-2003 [Tesis de Maestría sin publicar, FLACSO México.].

Navarro, M. y C. Varetto (2014). La estructura de competencia partidaria Argentina: análisis y evaluación de la imagen analítica de la 'territorialización' del sistema de partidos. En Revista Chilena de Derecho y Ciencia Política 5 (1), 109-147.

Nohlen, D. 1994. Sistemas electorales y partidos políticos. México: FCE.

Panebianco, A. (1990). Modelos de partidos. Organización y poder en los partidos políticos. Madrid: Alianza.

Rae, D. (1967). The Political Consequences of Electoral Laws. Nueva Haven y Landon: Yale University Press

Reynoso, D. (2011). La estrategia dominante. Alianzas electorales en los estados mexicanos 1988-2011. Buenos Aires: Teseo-FLACSO Argentina.

Rock, D. (1977). El radicalismo argentino. Buenos Aires: Amorrortu.

Stefuriuc, I. (2013). Government Formation in Multi-Level Settings: Party Strategy and Institutional Constraints. Nueva York: Palgrave MacMillan.

Suárez Cao, J., M. Batlle y L. Wills-Otero (2017). El auge de los estudios sobre la política subnacional en latinoamérica. En Revista Colombia Internacional 90 (abriljunio), 15-34.

Varetto, C. (2017). Las múltiples vidas del sistema de partidos en Argentina. Villa María: Eduvim.

Zelaznik, J. (2013). Unión Cívica Radical: entre el Tercer Movimiento Histórico y la lucha por la subsistencia. En Revista SAAP 7 (2), 423-431.

Zelaznik, J. (2001). The Building of Coalitions in the Presidential Systems of Latin America: An Inquiry into the Political Conditions of Governability [Tesis Doctoral sin publicar, Department of Government, University of Essex.]. 


\title{
Palabras clave
}

coaliciones electorales - Argentina - partidos políticos - competencia electoral — sistema de partidos

\begin{abstract}
Argentina's competitive dynamic has acquired a coalitional component in the last two decades. After the constitutional reform of 1994, more and more political parties privilege the formation of joint agreements with different partners to compete for public office at stake. The present work aims to propose that the construction of electoral coalitions is a strategic decision of the party elites. They can privilege two different models of construction: doing it by territorial penetration or by territorial diffusion. The privileged model impacts on the degree of electoral agreement reached by party elites. I apply this analysis to the presidential coalitions and national deputies that competed in the country between 1995 and 2015.
\end{abstract}

\section{Keywords}

electoral coalitions — Argentina — party politics — electoral competition — party systems 